\title{
Abnormal Systemic and Ocular Vascular Response to Temperature Provocation in Primary Open-Angle Glaucoma Patients: A Case for Autonomic Failure?
}

\author{
Doina Gherghel, ${ }^{1,2}$ Sarab Louise Hosking, ${ }^{1,2}$ and Ian Andrew Cunliffe ${ }^{2}$
}

Purpose. To assess systemic and ocular vascular reactivity in response to warm and cold provocation in untreated patients with primary open-angle glaucoma and normal control subjects.

Methods. Twenty-four patients with primary open-angle glaucoma and 22 normal control subjects were subjected to a modified cold pressor test involving immersion of the right hand in $40^{\circ} \mathrm{C}$ warm water followed by $4^{\circ} \mathrm{C}$ cold water exposure, and finger and ocular blood flow were assessed by means of peripheral laser Doppler flowmetry and retinal flowmetry, respectively. Finger and body temperature as well as intraocular pressure, systemic blood pressure, systemic pulse pressure, heart rate, and ocular perfusion pressure were also monitored.

REsults. The patients with glaucoma demonstrated an increase in diastolic blood pressure $(P=0.023)$, heart rate $(P=0.010)$, and mean ocular perfusion pressure $(P=0.039)$ during immersion of the tested hand in $40^{\circ} \mathrm{C}$ water. During cold provocation, the patients demonstrated a significant decrease in finger $(P=0.0003)$ and ocular blood flow (the parameter velocity measured at the temporal neuroretinal rim area; $P=$ 0.021 ). Normal subjects did not demonstrate any blood flow or finger temperature changes during immersion of the tested hand in $40^{\circ} \mathrm{C}$ water $(P>0.05)$; however, they exhibited increases in systolic blood pressure $(P=0.034)$ and pulse pressure $(P=$ $0.0009)$ and a decrease in finger blood flow $(P=0.0001)$ during cold provocation. In normal subjects, the ocular blood flow was unchanged during high- and low-temperature challenge.

Conclusions. Cold provocation elicits a different blood pressure, and ocular blood flow response in patients with primary open-angle glaucoma compared with control subjects. These findings suggest a systemic autonomic failure and ocular vascular dysregulation in POAG patients. (Invest Ophthalmol Vis Sci. 2004;45:3546-3554) DOI:10.1167/iovs.04-0290

$\mathrm{n}$ the search for risk factors involved in the pathogenesis of Ilaucoma, vascular risk factors are the most extensively studied variables other than increased intraocular pressure (IOP). In particular, a vascular dysregulation leading to local vasospasm or impaired autoregulation has been advocated as a possible contributing factor in the etiology of primary openangle glaucoma (POAG). ${ }^{1-5}$

From the ${ }^{1}$ Neuroscience Research Institute, School of Life and Health Sciences, Aston University, Aston Triangle, Birmingham, United Kingdom; and ${ }^{2}$ Department of Ophthalmology, Heartlands and Solihull National Health Service Trust, Birmingham, United Kingdom.

Submitted for publication March 15, 2004; revised April 26, 2004; accepted May 27, 2004.

Disclosure: D. Gherghel, None; S.L. Hosking, None; I.A. Cunliffe, None

The publication costs of this article were defrayed in part by page charge payment. This article must therefore be marked "advertisement" in accordance with 18 U.S.C. $\$ 1734$ solely to indicate this fact.

Corresponding author: Sarah Louise Hosking, Neuroscience Research Institute, School of Life and Health Sciences, Aston University, Aston Triangle, Birmingham B4 7ET, UK; s.l.hosking@aston.ac.uk.
Among the factors that may influence blood flow physiology in the human body, variables such as blood pressure (BP) and heart rate $(\mathrm{HR})$ are regulated by the autonomic nervous system (ANS). ${ }^{6}$ It follows that any autonomic disturbances could have severe hemodynamic consequences. POAG itself has also been directly linked to ANS dysfunctions. Systemic parasympathetic and sympathetic neuropathies have been reported in patients with POAG and in those with normal tension glaucoma (NTG), ${ }^{7-10}$ and it has already been suggested that disturbed autonomic activity may play a role in the pathogenesis of the glaucomatous damage. Nevertheless, further research is needed to prove a direct relationship between glaucoma and ANS failure.

Besides other autonomic function tests, such as the measurement of heart rate variability (HRV), Valsalva maneuver, ${ }^{11}$ pressor drug infusion, ${ }^{12}$ lower body negative pressure, neck chamber pressure, head-upright tilt, ${ }^{13,14}$ and handgrip stress, ${ }^{15}$ cold stimulation is also a well-established provocation test used in detecting abnormal vascular reactivity in patients with autonomic failure. ${ }^{16}$ The so-called cold pressor test (CPT) generally involves immersion of one hand in cold water with different temperatures (ranging from $0-15^{\circ} \mathrm{C}$ ) and is a well-known stress test that induces a reproducible sympathetic activation in both normal subjects and subjects with arterial hypertension. ${ }^{17,18}$ Some of the physiological responses to this test include arteriolar vasoconstriction, increased BP and plasma catecholamines, and reduction in peripheral blood flow. ${ }^{19} \mathrm{~A}$ well-known variation of the CPT involves immersion of the right upper limb in $40^{\circ} \mathrm{C}$ warm water followed by cooling of the hand. ${ }^{20-22}$

Although cold provocation has a dramatic effect on the systemic vasculature, little is known about its consequences on ocular blood flow. Rojanapongpun and Drance ${ }^{21}$ and Nicolela et al. ${ }^{23}$ failed to report any blood flow changes as a response to cold stimulation in the ophthalmic artery and retinal circulation of patients with POAG. Nevertheless, in patients with vascular dysregulation manifested by peripheral vasospasm, visual field (VF) defects have been reported after cold provocation $^{1,24}$; it has been suggested that this effect could be the result of an ocular circulatory insufficiency. Because vascular dysregulation has been demonstrated to play a role in the pathogenesis of glaucomatous neuropathy, ${ }^{1-5}$ we can hypothesize that cold stimulation could result in an abnormal hemodynamic response in ocular vascular beds. In the present study we sought to assess the systemic vascular reactivity as well as retinal and optic nerve head ocular blood flow (OBF) changes in response to warm and cold provocation in newly diagnosed and untreated POAG patients and normal control subjects.

\section{Subjects ANd Methods}

\section{Subjects}

Successive newly diagnosed and previously untreated POAG patients attending the Fast Track Glaucoma Clinic at the Heartlands and Solihull NHS Trust (Birmingham, UK) were recruited for the study. Patients underwent diurnal IOP phasing and POAG was diagnosed in the 
presence of IOP measurements greater than $21 \mathrm{~mm} \mathrm{Hg}$ by applanation tonometry (with at least two of the measurements being higher than 24 $\mathrm{mm} \mathrm{Hg}$ ), glaucomatous cupping of the optic disc on funduscopic examination, normal open anterior chamber angles by gonioscopy, and repeatable VF defects consistent with a diagnosis of glaucoma, using program 24-2 of the Humphrey Field Analyzer (HFA; Carl Zeiss Meditec, Dublin, CA). Patients with closed iridocorneal angles; evidence of secondary glaucoma; pseudoexfoliation; pigmentary dispersion; a history of intraocular surgery; any form of retinal or neuroophthalmologic disease that could result in visual field defects; or a history of chronic systemic disease, including diabetes mellitus, or occlusive vascular disorders were not included in the study. The normal control group was recruited from patients' spouses and included only those subjects who had never had any significant systemic or ocular disease, including chronic cardiovascular diseases and glaucoma. Further exclusion criteria for both groups were refractive errors higher than +2 or $-3 \mathrm{D}$, a medical history of Raynaud's phenomenon, neurologic or metabolic diseases, and chronic intake of vasoactive drugs. Before the study, ethical approval was obtained from the local medical ethics committee, and written informed consent was received from all subjects. The study was designed and conducted in accordance with the tenets of Declaration of Helsinki.

\section{Experimental Setup}

All subjects were tested in the morning, between 8 and $10 \mathrm{AM}$, in a room with a constant temperature, ranging between $21^{\circ} \mathrm{C}$ and $23^{\circ} \mathrm{C}$ (mean $\pm \mathrm{SD}: 21.31 \pm 1.15^{\circ} \mathrm{C}$ ). Subjects were instructed to avoid ingesting any stimulants, including coffee, tea, or cigarette smoke on the morning of the study. In preparation for the test, each subject rested in a sitting position for 15 to 20 minutes in a quiet room to achieve sufficient mental and physical calm. The experiment comprised five steps: (1) a 10-minute baseline period; (2) a 5-minute immersion of the right hand up to the wrist in $40^{\circ} \mathrm{C}$ water; (3) a 5- to 10-minute recovery period with the hand wrapped in a towel to avoid a cooling evaporation effect on hand temperature; (4) immersion of the right hand in ice water $\left(4^{\circ} \mathrm{C}\right)$ for 1 minute; and (5) a 15 -minute final recovery period, with the hand wrapped in a towel. During cold provocation, subjects were instructed to signal verbally when the water "begins to produce pain." The cold provocation was interrupted at the moment when pain occurred.

For each subject, peripheral finger blood flow (FBF) by means of peripheral laser Doppler flowmetry and finger temperature (FT) in the left hand were measured continuously during the experiment. In addition, IOP, tympanic temperature (TT), BP, heart rate (HR), and OBF parameters (volume, flow, and velocity) in the temporal areas of the neuroretinal rim (NRR) and peripapillary retina were assessed with the Heidelberg Retina Flowmeter (HRF; Heidelberg Engineering, GmbH, Heidelberg, Germany) at the end of each step of the experiment. The techniques are described later.

\section{Peripheral Blood Flow and Peripheral and Central Temperature}

Skin perfusion was assessed by means of a blood perfusion monitor (Periflux System 5001; Perimed, Stockholm, Sweden) that uses a lowpower solid-state laser diode as a coherent source of light. The optical output power at the probe end is less than $2 \mathrm{~mW}$ and the wavelength is typically $780 \mathrm{~nm}$. The apparatus and the technique have been described in detail by Nilsson et al. ${ }^{25,26}$ In summary, this device measures the microvascular perfusion using a laser beam that, when it strikes an object in motion (such as red blood cells), undergoes a change in light frequency known as the Doppler shift. All measurements were performed with an upper frequency limit of $32 \mathrm{kHz}$, an output circuit time constant of 0.2 second, and a gain factor of $\times 3$. For measurements of FBF, the probe was attached with an adhesive tape to the pulp of the second finger of the left hand. The hand of the seated subjects rested comfortably on a table, at heart level. The probe of the perfusion monitor was placed to avoid any undue pressure and kept in this position, so that the signal level indicator remained green. The FBF was then recorded continuously on a computer.

The FT was measured using a copper-constantan sensor (ML309 Thermistor Pod) connected to a signal acquisition unit (PowerLab/4SP unit; A\&D Instruments Ltd., Oxford, UK). This type of sensor is isolated from the environment with neoprene and is suitable for skin temperature measurements in the range of $5^{\circ}$ to $45^{\circ} \mathrm{C}$. The sensor was fixed with a thin layer of adhesive tape on the dorsal aspect of the second finger of the left hand near the area of peripheral blood flow measurement. The signal acquisition unit was connected to a computer, permitting continuous recording of peripheral temperature during the experiment.

FBF and FT were measured continuously during the experiment, and average levels were calculated for each step of the experiment.

A noncontact infrared ear thermometer (ThermoTek One Second Tympanic Thermometer, P.M.S. Instruments Ltd., Maidenhead, UK) was used to measure body temperature. Within 1 second, the noncontact infrared ear thermometer measures tympanic temperature, which represents core body temperature. This device can evaluate temperatures between $20^{\circ} \mathrm{C}$ and $42.2^{\circ} \mathrm{C}$ and works by detecting infrared energy emitted from the deep auditory canal and tympanic membrane. Infrared ear thermometry findings are reproducible and provide a relatively close estimate of pulmonary artery core temperature. ${ }^{27,28}$

\section{Systemic BP and HR}

Clinical BP and HR were obtained with an automatic BP monitor (UA-779; A\&D Instruments Ltd.). This device measures BP automatically, using the same principle as a conventional mercury sphygmomanometer, with a cuff and microphone. During the BP measurements, the cuff was placed around the upper right arm approximately at heart level. The systolic BP (SBP) and diastolic BP (DBP) were measured three times ( 1 minute apart), and the average readings for SBP and DBP were then used to calculate the mean BP (MBP) using the formula: $\mathrm{MBP}=2 / 3 \mathrm{DBP}+1 / 3 \mathrm{SBP}$. Pulse pressure $(\mathrm{PP})$ was calculated as: $\mathrm{PP}=\mathrm{SBP}-\mathrm{DBP}$.

\section{Intraocular Pressure}

Because the design of the experiment did not allow the patient to be seated at a slit lamp, IOP was measured by a handheld tonometer (Tono-Pen XL; Mentor Ophthalmics Inc., Norwell, MA) after application of 1 drop of $0.4 \%$ benoxinate hydrochloride. The IOP and MBP measurements were used to calculate the mean ocular perfusion pressure $($ MOPP): MOPP $=2 / 3($ MBP - IOP $)$.

\section{Ocular Blood Flow}

In the glaucoma patients, measurements were performed in the eye with the most advanced disease (as determined by ophthalmoscopy and $\mathrm{VF}$ analysis). In normal subjects, the test eye was randomly selected. Perfusion parameters in the superior temporal regions of the neuroretinal rim and peripapillary retina were measured for each step of the experiment, using the HRF system. The HRF principle has been described in detail. ${ }^{29,30}$ In short, this noninvasive technique combines laser Doppler flowmetry using an infrared laser diode with wavelength of $780 \mathrm{~nm}$ and a power of $200 \mu \mathrm{W}$, with the confocal scanning laser principle. The HRF scanning system enables the measurement of backscattered intensity for a retinal area of approximately $2.7 \times 0.7 \mathrm{~mm}$ $\left(10^{\circ} \times 2.5^{\circ} \mathrm{scan}\right)$, mapped with a resolution of 256 points $\times 64$ lines. ${ }^{29}$ The total time for scanning and data acquisition is 2.048 seconds. Each of the 64 horizontal lines is scanned 128 times with a line repetition rate of $4000 \mathrm{~Hz}$. For each retinal point in the scanned area, the back-scattered intensity can be measured as a function of time to produce an intensity-time curve. The signal undergoes a fast-Fourier transformation, which results in a power spectrum for each retinal point. This spectrum is used to calculate the variables volume, flow, and velocity for each retinal point, expressed as the mean and SD of 
the measurements and displayed in arbitrary units. In this study, capillary volume, flow, and velocity were recorded for all images with a $10 \times 10$-pixel measurement frame, avoiding areas with large vessels.

To collect HRF data, we needed to define the border between the cup and the rim as well as the disc margin. For this purpose, we used a confocal laser retinal tomograph, the Heidelberg Retina Tomograph (HRT; Heidelberg Engineering). The method used by this device has been described in detail. ${ }^{31-37}$ In short, this instrument is a confocal scanning laser $(670 \mathrm{~nm})$ ophthalmoscope that obtains topographic images as a series of 32 optical sections perpendicular to the optical axis of the eye at consecutive focal planes. The image consists of $256 \times$ 256 pixels, and at each pixel the retinal height is determined. Based on Gullstrand's model eye, magnification error is corrected using the patient's keratometric readings. In eligible eyes, after keratometric values were measured, one topographic image was obtained through a dilated pupil ( $1 \%$ tropicamide; Alcon, Fort Worth, TX). This is in contrast to the standard protocol of three images. ${ }^{38}$ However, because of the principal of regression to the mean, limiting the number of acquired topographic images to one image per eye is not expected to alter the results in a screening procedure such as the one used in this study. ${ }^{39}$

During the imaging procedure, the subjects fixated on a distant target with the fellow (nontest) eye. For the topographic images, the optic disc margin was outlined along the inner margin of the scleral ring by an experienced investigator (DG). With a transparency overlaid on the monitor's screen, anatomic landmarks (blood vessels, optic nerve contour, and contour of the cup) were drawn manually. ${ }^{40}$

Three to five HRF measurements were recorded by the same experienced investigator (DG) at the end of each step of the experiment. Only the best-quality images were selected for statistical purposes. Quality inclusion criteria were lack of movement during the recording and good illumination of the image. Images were included if the direct current (DC) values were between 70 and $200 .{ }^{41,42}$ Measurements were performed, first on one location on the temporal NRR (TNRR) by a central alignment technique, ${ }^{43}$ and then on one location on the temporal retina (TR) while avoiding the large vessels. The transparency obtained on HRT measurements was overlaid on the HRF images of the same subject, ensuring a near-perfect adjustment. A $10^{\circ}$ frame was then drawn on the area of interest. The same transparency was used for all subsequent images obtained from the same subject during the experiment, to ensure that the exact location of the measurement frames was reproduced.

\section{Statistical Analysis}

Data are expressed as the mean \pm SD. Differences between the groups at baseline were calculated using Student's $t$-test for unpaired variables. Warm- and cold-induced changes were calculated using repeated-measurements ANOVA (re-ANOVA) followed by post hoc analysis using the Tukey honest significant difference (HSD) test. Peripheral blood flow and temperature were corrected for the influence of the ambiance and central temperatures. OBF was corrected for changes in MOPP in an analysis of covariance (ANCOVA). This approach was performed in a multivariate analysis, to ensure independence of the change at each step from the other changes in re-ANOVA. Pearson's linear correlation factor was used to study the relationship between changes in peripheral and ocular blood flow parameters. Holm's sequentially rejective method was used to correct for multiple comparisons. ${ }^{44}$ Statistical analyses were performed on computer (Statistica, ver. 6.0 for Windows; StatSoft, Tulsa, OK). Statistical significance was defined as $P<$ 0.05 .

\section{Results}

Thirty-two glaucoma patients (12 men and 20 women) and 34 control subjects (20 men and 14 women) participated in the experiment. In one case (a normal subject, male) the test had to be stopped after 30 seconds of cold provocation due to pain sensation, and the subject was excluded from the experiment. Careful image analysis and subsequent rejection of those sub-

TABLE 1. Systemic BP, HR, IOP, and Central Temperature in the Study Groups

\begin{tabular}{lcccc}
\hline Parameter & $\begin{array}{c}\text { Glaucoma } \\
\text { (24 Patients) }\end{array}$ & $\begin{array}{c}\text { Normal } \\
\text { (22 Subjects) }\end{array}$ & $\boldsymbol{P}$ & $\boldsymbol{P}^{*}$ \\
\hline At baseline & & & & \\
IOP (mm Hg) & $23.63 \pm 4.89$ & $17.95 \pm 3.74$ & 0.00005 & 0.0004 \\
SBP (mm Hg) & $134.46 \pm 18.90$ & $127.95 \pm 21.95$ & 0.28600 & NS \\
DBP (mm Hg) & $76.04 \pm 11.80$ & $77.73 \pm 9.83$ & 0.60300 & NS \\
MBP (mm Hg) & $95.51 \pm 13.29$ & $94.47 \pm 13.01$ & 0.78900 & NS \\
PP (mm Hg) & $58.42 \pm 12.61$ & $50.23 \pm 15.84$ & 0.05800 & NS \\
MOPP (mm Hg) & $39.63 \pm 8.56$ & $44.30 \pm 9.92$ & 0.09400 & NS \\
HR (beats/min) & $66.35 \pm 12.06$ & $68.86 \pm 9.09$ & 0.43500 & NS \\
TT ( ${ }^{\circ}$ C) & $35.59 \pm 0.62$ & $35.65 \pm 0.48$ & 0.70700 & NS \\
After warm stimulation & & & & \\
IOP (mm Hg) & $23.42 \pm 4.99$ & $17.68 \pm 3.27$ & 0.00004 & 0.0003 \\
SBP (mm Hg) & $135.67 \pm 24.40$ & $126.77 \pm 21.80$ & 0.20000 & NS \\
DBP (mm Hg) & $81.08 \pm 16.50$ & $79.68 \pm 12.69$ & 0.75000 & NS \\
MBP (mm Hg) & $99.28 \pm 18.55$ & $95.38 \pm 15.32$ & 0.44400 & NS \\
MOPP (mm Hg) & $42.77 \pm 11.22$ & $45.90 \pm 11.27$ & 0.34500 & NS \\
PP (mm Hg) & $54.58 \pm 12.68$ & $47.09 \pm 11.79$ & 0.04400 & NS \\
HR (beats/min) & $69.29 \pm 12.53$ & $69.59 \pm 8.82$ & 0.92600 & NS \\
TT ( ${ }^{\circ}$ C) & $35.57 \pm 0.60$ & $35.67 \pm 0.49$ & 0.71000 & NS \\
After cold stimulation & & & & \\
IOP (mm Hg) & $23.96 \pm 4.63$ & $18.27 \pm 3.72$ & 0.00004 & 0.0003 \\
SBP (mm Hg) & $134.21 \pm 18.55$ & $133.04 \pm 17.26$ & 0.82700 & NS \\
DBP (mm Hg) & $78.33 \pm 13.02$ & $78.77 \pm 10.40$ & 0.90100 & NS \\
MBP (mm Hg) & $96.96 \pm 13.54$ & $96.86 \pm 11.89$ & 0.98000 & NS \\
MOPP (mm Hg) & $40.68 \pm 8.58$ & $46.30 \pm 9.25$ & 0.03800 & NS \\
PP (mm Hg) & $55.88 \pm 14.16$ & $54.27 \pm 11.62$ & 0.67800 & NS \\
HR (beats/min) & $66.52 \pm 13.63$ & $67.54 \pm 7.63$ & 0.76200 & NS \\
TT ( ${ }^{\circ}$ C) & $35.53 \pm 0.70$ & $35.64 \pm 0.40$ & 0.85800 & NS \\
\hline
\end{tabular}

* Corrected by means of Holm's sequentially rejective method. 
TABLE 2. Peripheral Temperature and Peripheral and Ocular Blood Flow Parameters

\begin{tabular}{|c|c|c|c|c|}
\hline Parameter & $\begin{array}{c}\text { Glaucoma } \\
\text { (24 patients) }\end{array}$ & $\begin{array}{c}\text { Normal } \\
\text { (22 } \text { subjects) }\end{array}$ & $\boldsymbol{P}$ & $\boldsymbol{P}^{*}$ \\
\hline \multicolumn{5}{|l|}{ At baseline } \\
\hline FT $\left({ }^{\circ} \mathrm{C}\right)$ & $32.26 \pm 3.35$ & $34.27 \pm 2.66$ & 0.030 & NS \\
\hline $\mathrm{FBF}(\mathrm{AU})$ & $218.70 \pm 129.42$ & $297.90 \pm 144.16$ & 0.056 & NS \\
\hline Volume TNRR (AU) & $13.44 \pm 4.08$ & $12.81 \pm 2.69$ & 0.565 & NS \\
\hline Flow TNRR (AU) & $236.43 \pm 86.97$ & $212.83 \pm 52.18$ & 0.317 & NS \\
\hline Velocity TNRR (AU) & $0.76 \pm 0.38$ & $0.76 \pm 0.18$ & 0.983 & NS \\
\hline Volume TR (AU) & $16.55 \pm 3.74$ & $16.90 \pm 2.66$ & 0.730 & NS \\
\hline Flow TR (AU) & $292.58 \pm 88.72$ & $317.97 \pm 79.52$ & 0.339 & NS \\
\hline Velocity TR (AU) & $1.04 \pm 0.30$ & $1.14 \pm 0.27$ & 0.312 & NS \\
\hline \multicolumn{5}{|l|}{ After warm stimulation } \\
\hline FT $\left({ }^{\circ} \mathrm{C}\right)$ & $32.81 \pm 3.41$ & $34.48 \pm 2.59$ & 0.070 & NS \\
\hline $\mathrm{FBF}(\mathrm{AU})$ & $211.46 \pm 124.60$ & $263.72 \pm 142.78$ & 0.192 & NS \\
\hline Volume TNRR (AU) & $13.04 \pm 4.37$ & $11.90 \pm 2.98$ & 0.368 & NS \\
\hline Flow TNRR (AU) & $226.97 \pm 88.74$ & $205.46 \pm 42.12$ & 0.367 & NS \\
\hline Velocity TNRR (AU) & $0.80 \pm 0.30$ & $0.74 \pm 0.15$ & 0.480 & NS \\
\hline Volume TR (AU) & $17.00 \pm 3.68$ & $16.87 \pm 3.69$ & 0.912 & NS \\
\hline Flow TR (AU) & $294.43 \pm 83.60$ & $318.56 \pm 67.83$ & 0.330 & NS \\
\hline Velocity TR (AU) & $1.04 \pm 0.29$ & $1.14 \pm 0.23$ & 0.265 & NS \\
\hline \multicolumn{5}{|l|}{ After cold stimulation } \\
\hline FT $\left({ }^{\circ} \mathrm{C}\right)$ & $32.77 \pm 3.48$ & $34.25 \pm 2.60$ & 0.112 & NS \\
\hline $\mathrm{FBF}(\mathrm{AU})$ & $131.15 \pm 96.10$ & $151.44 .90 \pm 119.31$ & 0.527 & NS \\
\hline Volume TNRR (AU) & $13.29 \pm 4.71$ & $12.05 \pm 3.35$ & 0.383 & NS \\
\hline Flow TNRR (AU) & $209.11 \pm 78.09$ & $223.64 \pm 57.36$ & 0.533 & NS \\
\hline Velocity TNRR (AU) & $0.73 \pm 0.24$ & $0.81 \pm 0.22$ & 0.349 & NS \\
\hline Volume TR (AU) & $14.82 \pm 4.16$ & $16.76 \pm 3.07$ & 0.125 & NS \\
\hline Flow TR (AU) & $280.71 \pm 90.71$ & $300.01 \pm 79.60$ & 0.504 & NS \\
\hline Velocity TR (AU) & $1.00 \pm 0.32$ & $1.08 \pm 0.27$ & 0.547 & NS \\
\hline
\end{tabular}

* Corrected by means of Holm's sequentially rejective method.

jects who exhibited poor HRF image quality resulted in further exclusion of eight glaucoma patients ( 3 men and 5 women) and 11 control subjects ( 6 men and 5 women). Finally, 24 glaucoma patients $(9$ men and 15 women, mean age \pm SD: $68.38 \pm 11.92$ years) and 22 normal subjects (13 men and 9 women, mean age \pm SD: $62.59 \pm 9.43$ years) were included in the statistical analysis.

\section{Baseline Data}

There was no significant difference in age between study groups $(P>0.05)$. Moreover, the number of men and women included in the study groups were similar $\left(P>0.05, \chi^{2}\right.$ test $)$. Table 1 shows the systemic hemodynamic parameters (BP, PP, MOPP, HR), as well as IOP, and TT for both study groups. Peripheral and ocular blood flow parameters and FT are summarized in Table 2 . The IOP was significantly higher $(P=$ $0.0004)$ in the untreated glaucoma patients than in normal subjects. There were no significant differences between study groups with regard to systemic BP, PP, MOPP, HR, and central temperature $(P>0.05$, Table 1$)$. Moreover, the study groups were also comparable with regard to FT, FBF, and OBF parameters (flow, velocity, volume; $P>0.05$, Table 2 ).

\section{Warm Stimulation}

Normal Subjects. In normal subjects, warm stimulation did not have any effect on any systemic or ocular measured parameters when compared with baseline $(P>0.05)$.

Glaucoma Patients. Warm stimulation resulted in a significant increase in DBP (mean change \pm SD: $6.56 \pm 13.40, P=$ 0.023 ), HR, (mean change $\pm \mathrm{SD}: 5.40 \pm 8.06, P=0.010$ ), and MOPP (mean change \pm SD: $6.68 \pm 19.72, P=0.039$ ) compared with baseline (Fig. 1). OBF parameters, however, remained unchanged after immersion of the right hand in $40^{\circ} \mathrm{C}$ warm water $(P>0.05$, after correcting for the influence of MOPP).

Intergroup Differences. Intergroup differences in the measured systemic, peripheral, and ocular parameters after warm stimulation are listed in Tables 1 and 2 . The only statistically significant difference between groups was in the level of IOP $(P=0.0005)$. The changes between baseline and warm stimulation are shown in Tables 3 and 4 . There were no statistically significant differences between the two study groups $(P>0.05)$.

\section{Cold Stimulation}

Normal Subjects. In normal subjects, immersion of the right hand in $4^{\circ} \mathrm{C}$ cold water for 1 minute resulted in a statistically significant increase in SBP (mean change \pm SD: $4.65 \pm$ $2.53, P=0.034$ ) and PP (mean change \pm SD: $11.58 \pm 16.58$, $P=0.0009$ ) compared with baseline (Fig. 1). The cold provocation also resulted in a significant decrease in FBF compared with baseline (mean change \pm SD: $-50.86 \pm 26.01, P=$ 0.0001 , Fig. 2). In normal subjects, however, cold stimulation did not influence the OBF parameters.

Glaucoma Patients. IOP, systemic BP, PP, MOPP, and HR were not significantly modified by cold stimulation; however, after correcting for the influence of room and body temperature, there was a significant decrease in FBF (mean change \pm SD: $-29.95 \pm 44.67, P=0.0003$, Fig. 2) compared with baseline. In the glaucoma group, cold stimulation determined a significant decrease in the parameter velocity (mean change \pm SD: $15.55 \pm 22.67, P=0.021$, Fig. 3) measured at the TNRR level. These changes were significant after correction for the influence of MOPP on these parameters.

Intergroup Differences. Intergroup differences in the measured systemic, peripheral, and ocular parameters after immersion of the right hand in $4{ }^{\circ} \mathrm{C}$ cold water for 1 minute are 

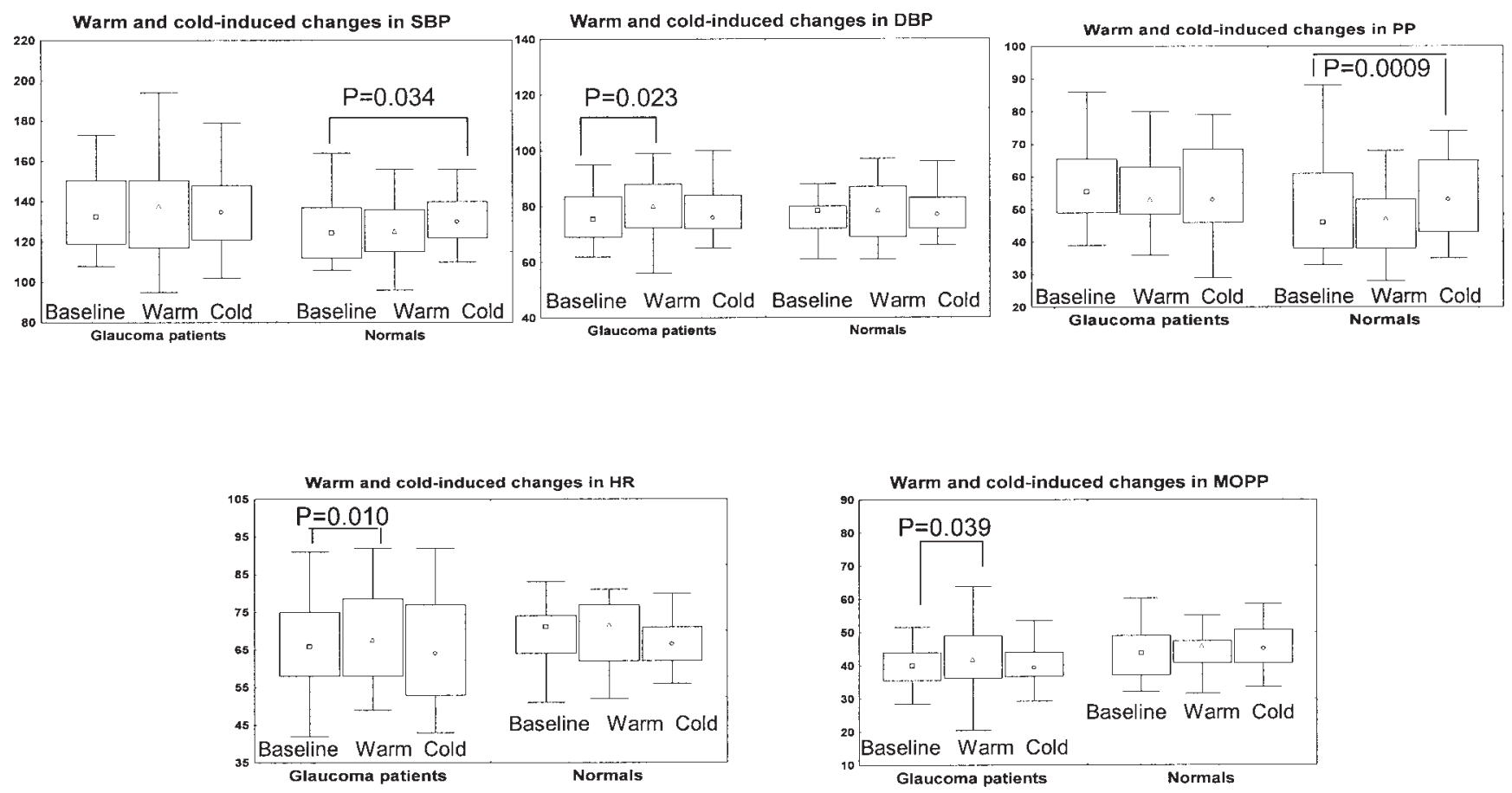

FiguRE 1. Warm- and cold-induced changes in systemic blood pressure, heart rate, and mean ocular perfusion pressure in glaucoma patients and normal control subjects.

listed in Tables 1 and 2 . The only statistically significant difference between groups was in IOP $(P=0.0003)$.

Intergroup differences in cold-induced changes (percentage of baseline values) are listed in Tables 3 and 4 . These changes were comparable between study groups for all the measured parameters $(P>0.05)$ with the exception of PP. Normal subjects exhibited higher PP changes from baseline values than glaucoma during cold provocation $(P=0.021)$.

The percent change in FBF did not correlate with changes in the measured ocular blood flow parameters for the same stage of the experiment in either of experimental groups $(P>$ $0.05)$.

\section{Discussion}

The present study assessed the response of BP as well as peripheral and ocular blood flow to warm and cold provocation. Our results disclosed a difference in the systemic and ocular vascular response to these stimuli between untreated POAG patients and otherwise healthy age-matched control subjects. Whereas DBP, HR, and MOPP increased during immersion of the test hand in $40^{\circ} \mathrm{C}$ water in POAG patients, in control subjects, SBP and PP increased markedly during cold provocation. Moreover, in glaucoma patients, cold stimulation did not affect systemic BP; however, it resulted in a significant reduction in blood velocity at the TNRR level. No OBF changes were observed in normal subjects after cold provocation. Cold provocation resulted in a similar reduction in FBF in both study groups.

The CPT is a well-known and widely used provocation test able to determine the integrity of the ANS function. Similar tests include the Valsalva maneuver, ${ }^{11}$ pressor drug infusion, ${ }^{12}$ lower body negative pressure, neck chamber pressure, headupright tilt, ${ }^{13,14}$ and handgrip stress. ${ }^{15}$ The initial normal response to CPT consists of cutaneous vasoconstriction and an increase in systemic BP. A blunt BP response to CPT may indicate autonomic dysregulation. ${ }^{19,45}$ In our study, glaucoma patients exhibited high DBP and HR during warm but not cold provocation. This observation is of extreme interest. It is thought that the vascular responses to warm immersion are the

TABLE 3. Intergroup Differences in Warm- and Cold-Induced Changes

\begin{tabular}{|c|c|c|c|c|c|c|c|}
\hline \multirow[b]{2}{*}{ Parameter } & \multicolumn{2}{|c|}{ Warm-Induced Changes } & \multirow[b]{2}{*}{$\boldsymbol{P}$} & \multicolumn{2}{|c|}{ Cold-Induced Changes } & \multirow[b]{2}{*}{$\boldsymbol{P}$} & \multirow[b]{2}{*}{$\boldsymbol{P}^{*}$} \\
\hline & Glaucoma & Normal & & Glaucoma & Normal & & \\
\hline IOP & $-2.52 \pm 4.02$ & $-1.32 \pm 3.56$ & 0.294 & $1.80 \pm 4.57$ & $1.63 \pm 3.52$ & 0.886 & NS \\
\hline SBP & $0.87 \pm 11.36$ & $-0.75 \pm 7.13$ & 0.570 & $0.04 \pm 6.28$ & $4.65 \pm 2.53$ & 0.015 & NS \\
\hline DBP & $6.56 \pm 13.40$ & $2.37 \pm 7.82$ & 0.208 & $3.05 \pm 5.39$ & $1.39 \pm 6.51$ & 0.273 & NS \\
\hline MBP & $3.80 \pm 11.85$ & $0.81 \pm 6.27$ & 0.297 & $1.61 \pm 5.67$ & $2.78 \pm 4.32$ & 0.458 & NS \\
\hline PP & $-5.93 \pm 15.94$ & $-3.34 \pm 18.43$ & 0.611 & $-3.82 \pm 16.66$ & $11.58 \pm 16.58$ & 0.003 & 0.021 \\
\hline MOPP & $6.78 \pm 19.72$ & $1.84 \pm 10.49$ & 0.302 & $1.62 \pm 5.97$ & $3.34 \pm 6.47$ & 0.354 & NS \\
\hline $\mathrm{HR}$ & $5.40 \pm 8.06$ & $1.35 \pm 6.92$ & 0.077 & $0.56 \pm 7.13$ & $-1.27 \pm 8.78$ & 0.458 & NS \\
\hline
\end{tabular}

Data are expressed as a percentage of baseline.

* Corrected by means of Holm's sequentially rejective method. 
TABLE 4. Intergroup Differences in Warm and Cold-Induced Changes

\begin{tabular}{|c|c|c|c|c|c|c|}
\hline \multirow[b]{2}{*}{ Parameter } & \multicolumn{2}{|c|}{ Warm-Induced Changes } & \multirow[b]{2}{*}{$\boldsymbol{P}$} & \multicolumn{2}{|c|}{ Cold-Induced Changes } & \multirow[b]{2}{*}{$\boldsymbol{P}$} \\
\hline & Glaucoma & Normal & & Glaucoma & Normal & \\
\hline TT & $0.01 \pm 0.01$ & $-0.02 \pm 0.01$ & 0.897 & $0.05 \pm 0.04$ & $0.02 \pm 0.03$ & 0.833 \\
\hline FT & $1.75 \pm 3.28$ & $0.65 \pm 1.19$ & 0.144 & $1.17 \pm 4.08$ & $-0.01 \pm 2.32$ & 0.236 \\
\hline FBF & $7.21 \pm 50.31$ & $-9.44 \pm 28.60$ & 0.180 & $-29.95 \pm 44.67$ & $-50.86 \pm 26.01$ & 0.062 \\
\hline Volume TNRR & $2.68 \pm 17.87$ & $-4.32 \pm 16.40$ & 0.243 & $3.67 \pm 29.38$ & $-9.43 \pm 12.47$ & 0.485 \\
\hline Flow TNRR & $-0.06 \pm 25.49$ & $0.57 \pm 27.27$ & 0.944 & $-12.84 \pm 27.10$ & $-6.22 \pm 23.61$ & 0.470 \\
\hline Velocity TNRR & $-1.40 \pm 24.41$ & $2.04 \pm 25.99$ & 0.691 & $-15.55 \pm 22.67$ & $-4.52 \pm 15.72$ & 0.135 \\
\hline Volume TR & $0.54 \pm 16.20$ & $1.25 \pm 8.89$ & 0.874 & $-10.13 \pm 28.31$ & $4.18 \pm 19.09$ & 0.103 \\
\hline Flow TR & $-1.02 \pm 13.98$ & $3.00 \pm 19.18$ & 0.459 & $-3.45 \pm 28.32$ & $-4.75 \pm 22.10$ & 0.885 \\
\hline Velocity TR & $-1.96 \pm 13.43$ & $2.61 \pm 18.44$ & 0.381 & $-3.72 \pm 26.58$ & $-5.06 \pm 21.20$ & 0.875 \\
\hline
\end{tabular}

Data are expressed as a percentage of baseline.

result of stimulation of the preoptico-anterior hypothalamic area in the brain. ${ }^{46}$ Severe whole-body heating results in an increased HR without changes in systemic BP, ${ }^{47}$ whereas mild heating has no influence on either HR or systemic BP. ${ }^{48}$ Changing the stimulated skin area further decreases the temperature effect on systemic BP. ${ }^{48}$ Therefore, the immersion of one hand in warm $\left(40^{\circ} \mathrm{C}\right)$ water for 5 minutes was unlikely to provoke any HR or BP changes in our subjects. Indeed, the control group did not exhibit any systemic circulatory changes during warm stimulation. The most obvious explanation for the high BP and HR during warm provocation in our glaucoma patients could be an anticipatory reaction to the physical stress. This reaction occurred even though the patients were allowed 15 to 20 minutes in a quiet room to achieve a sufficient mental and physical calm before the experiment. In the glaucoma patients, the hemodynamic response due to the anticipation of the test may have been stronger than the effect of the warm stimulation itself, and the result was an increase in BP and HR. The type of vascular hyperactivity exhibited by our patients is similar to that demonstrated in subjects at risk for cardiovascular diseases, in whom the anticipatory and recovery vascular responses are better predictors for subsequent circulatory disturbances than the direct stress-induced reactivity. ${ }^{49}$ Theoretically, we can hypothesize that in their normal daily life, glaucoma patients respond to challenge by cardiovascular reactions that last longer than in normal subjects. This type of

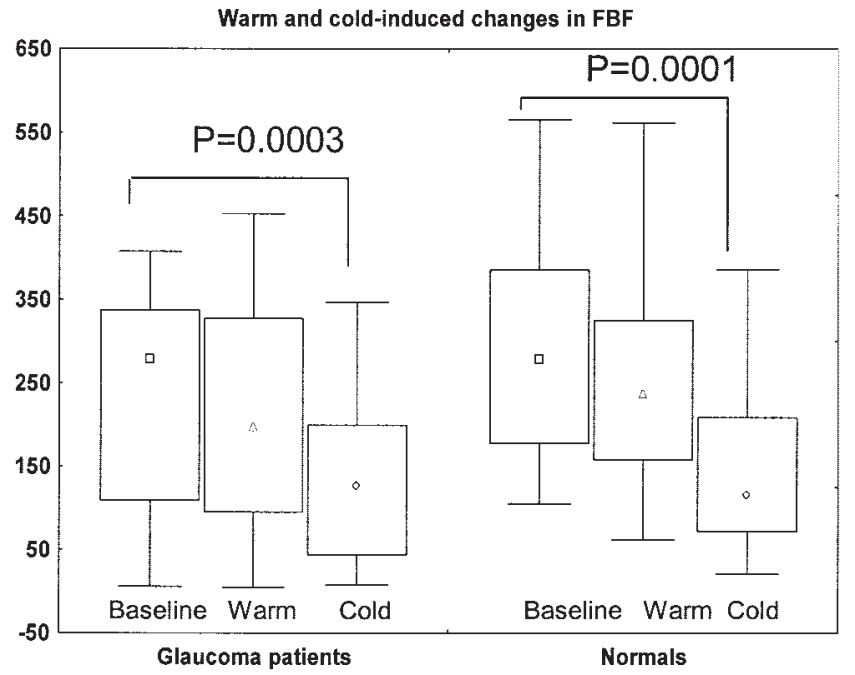

Figure 2. Warm and cold-induced changes in FBF in glaucoma patients and normal control subjects. reaction could in fact represent a sign of autonomic dysfunction. This conclusion is further supported by the observation that in our glaucoma patients, immersion of the tested hand in cold $\left(4^{\circ} \mathrm{C}\right)$ water did not affect the systemic BP. Similar results were reported by Nicolela et al. ${ }^{23}$ in POAG patients and control subjects after 30 minutes of body surface cooling. They observed that despite the increase in plasma endothelin (ET)-1, glaucoma patients did not exhibit any change in their systemic $\mathrm{BP}$, whereas control subjects demonstrated a significant increase in DBP and MOPP with cooling. The authors did not offer any explanation for this finding. We suggest that a blunted BP response to cold provocation in POAG patients could signal an abnormal neural pathway resulting from a lack of sympathetic participation. Whether this type of reaction has a role in glaucoma pathogenesis is still to be clarified.

Our study demonstrated an abnormal decrease of the blood velocity in the temporal region of the NRR after a 1-minute cold provocation in patients with POAG. To our knowledge, this is the first observation of an abnormal ocular hemodynamic response to cold provocation in POAG patients. Previous studies failed to report any OBF changes to CPT in either retrobulbar ${ }^{21}$ or retinal circulations. ${ }^{23}$ Our study also failed to demonstrate any hemodynamic changes in temporal peripapillary retinal circulation; however, cooling significantly decreased the blood velocity measured at the temporal NRR level. Because the vessels in the retina and in the prelaminar portion of the optic nerve have no neural innervation, ${ }^{50,51}$ it is reasonable to as-

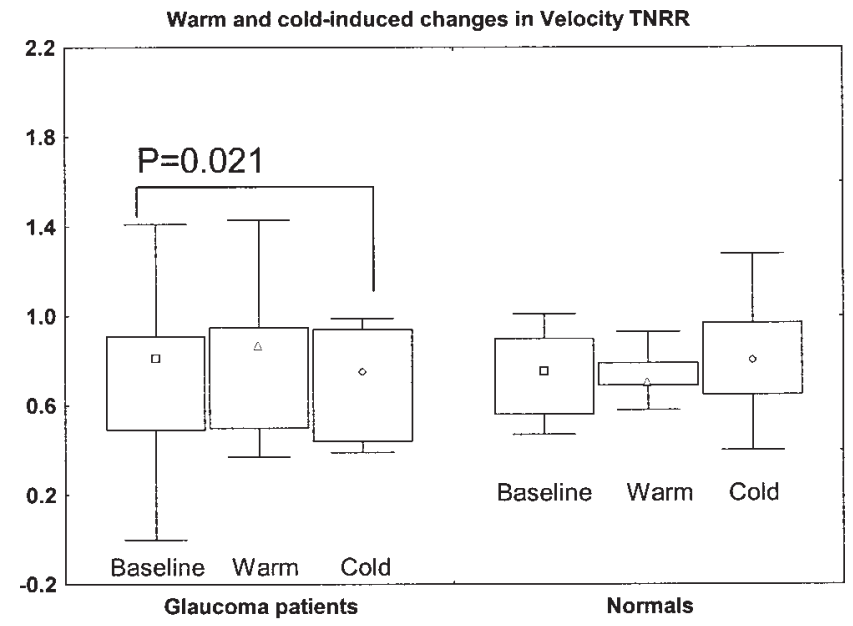

FIGURE 3. Warm- and cold-induced changes in the retinal flowmetry parameter Velocity, measured at the TNRR in glaucoma patients and normal control subjects. 
sume that a local neural-mediated vasoconstriction cannot explain our observation. We cannot exclude, however, a possible sympathetic influence on the blood flow downstream from the measurement point, at the level of posterior ciliary and central retinal arteries. These vessels have a rich supply of autonomic nerves $^{50,52,53}$ and could, in theory, react to a powerful vasoconstrictor stress such as CPT. Nevertheless, our glaucoma patients did not demonstrate a systemic sympathetic activation during cold provocation, as measured by an increase in systemic BP. Although activation of thermoreceptors in the skin during CPT could result in different activation of the arteries situated closer to the body's surface than of those situated away (e.g., ocular arteries), ${ }^{19}$ it is difficult to presume that in our patients, in that the sympathetic response to cooling manifested only at the retrobulbar vessels level. A more probable explanation would be the involvement of endothelial factors. Indeed, in a recently published study Nicolela et al. ${ }^{23}$ demonstrated a significant increase in ET-1 levels after body cooling in POAG patients. Although they failed to demonstrate any hemodynamic changes in the retinal circulation, they speculated that a high ET-1 concentration after CPT could influence the optic nerve blood flow. This conclusion does not come as a surprise. It has already been demonstrated that in humans, systemic injection of ET-1 results in a reduction of both pulsatile and optic nerve blood flow. ${ }^{54}$ Altered ocular blood flow during sympathetic provocation was also reported by other investigators. In a recent study, Gugleta et al. ${ }^{55}$ demonstrated that a handgrip stress is associated with a decrease in choroidal blood flow (CBF) in subjects with vasospasm and in POAG patients with progressive damage. They also hypothesized that an increased level of plasma ET-1 or a deficient release of endothelium-derived vasodilators could be responsible for the observed alteration in CBF during a handgrip test. Although we did not measure plasma ET-1 levels in our patients, in the light of previous research it is possible that high plasma levels of this extremely potent vasoconstrictor peptide resulted in a decreased blood flow at the NRR level in our glaucoma patients.

It can be argued that the observed vascular effects could be, at least partially, the result of a possible pain sensation associated with cold provocation. ${ }^{56}$ Indeed, CPT is not only a stressor commonly used to test sympathetic reaction but is also a widely used technique in pain research. When testing pain, however, CPT is rather unreliable. The pain triggered by this test is influenced by a large variety of factors, such as the individual ability to cope, ambient temperature, and mental preparation. ${ }^{57,58}$ In our study the room temperature was controlled and maintained between $21^{\circ} \mathrm{C}$ and $23^{\circ} \mathrm{C}$. In addition, our patients were instructed to signal verbally when the water "begins to produce pain." However, only one subject had to remove the hand from the cold water after 30 seconds due to pain sensation.

The mechanism by which the water's temperature relates to the response of nociceptors and pain perception is still incompletely understood. Other provocation tests, such as handgrip can also be painful. ${ }^{59}$ However, no significant relationship has been found between cardiovascular responses and perception of pain during handgrip test. ${ }^{60}$ Both handgrip stress and CPT have similar cardiovascular effects ${ }^{61}$; therefore, we can hypothesize that a possible pain sensation induced by cold provocation has limited value in determining the final cardiovascular response to this type of test.

In our study, optic nerve blood flow was assessed by means of HRF technology. This is a noninvasive, high-resolution mapping technique estimating capillary blood flow of the optic nerve head and retina with acceptable reliability ${ }^{62-64}$ and adequate ability to show blood flow alterations. ${ }^{65}$ Moreover, in our study we used a central alignment technique described by
Sehi and Flanagan, ${ }^{43}$ which allows an optimal focal plane for the flowmetry of the NRR and more repeatable measurements of the blood flow at this level. Using this technique, we observed that blood flow in the anterior optic nerve of glaucoma patients was normal under baseline conditions but became disturbed when challenged. This observation suggests that in glaucoma patients the blood flow may not be reduced continuously. If chronically reduced blood flow were able to induce glaucomatous damage, vascular diseases with chronic reduction in blood flow such as arteriosclerosis would have to be related to the prevalence of glaucoma. However, neither risk factors for arteriosclerosis nor arteriosclerotic alterations in the carotid vessels have been demonstrated to be related to the prevalence of glaucomatous optic neuropathy. ${ }^{66-70}$ An alternative explanation could be that these patients have ocular vascular dysregulation, which could predispose the optic nerve head to ischemia and reperfusion damage. Indeed, vascular dysregulation has been advocated as possible contributing factor in the etiology of POAG. ${ }^{5,71-74}$ The abnormal reduction of blood flow at the NRR in response to a stress factor such as cold could increase the susceptibility of the optic nerve to high IOP and low perfusion pressure in these individuals.

In summary, patients with POAG may show a blunted BP response and a reduction in optic nerve head blood flow in response to cold provocation. This reaction could be a manifestation of an autonomic dysfunction. The observed systemic and ocular hemodynamic alterations may result in the onset or progression of glaucomatous optic neuropathy.

\section{References}

1. Guthauser U, Flammer J, Mahler F. The relationship between digital and ocular vasospasm. Graefes Arch Clin Exp Ophthalmol. 1988;226:224-226.

2. Harris A, Sergott RC, Spaeth GL, Katz JL, Shoemaker JA, Martin BJ. Color Doppler analysis of ocular vessel blood velocity in normaltension glaucoma. Am J Opbthalmol. 1994;118:642-649.

3. Pillunat LE, Lang GK, Harris A. The visual response to increased ocular blood flow in normal pressure glaucoma. Surv Opbthalmol. 1994;38(suppl):S139-S147.

4. Flammer J, Pache M, Resink T. Vasospasm, its role in the pathogenesis of the diseases with particular reference to the eye. Prog Retin Eye Res. 2001;20:319-349.

5. Hosking SL, Harris A, Chung HS, et al. Ocular haemodynamic responses to induce hypercapnia and hyperoxia in glaucoma. $\mathrm{BrJ}$ Ophthalmol. 2004;88:406-411.

6. Appenzeller O, Orbie E. The Autonomic Nervous System. Amsterdam: Elsevier; 1997.

7. Clark CV, Mapstone R. Systemic autonomic neuropathy in openangle glaucoma. Doc Opbthalmol. 1986;64:179-185.

8. Kumar R, Ahuja VM. A study of changes in the status of autonomic nervous system in primary open angle glaucoma cases. Indian J Med Sci. 1999;53:529-534.

9. Brown CM, Dutsch M, Michelson G, Neundorfer B, Hilz M. Impaired cardiovascular responses to baroreflex stimulation in open angle and normal-pressure glaucoma. Clin Sci. 2002;102:623-630.

10. Riccadonna M, Covi G, Pancera P, et al. Autonomic system activity and 24-hour blood pressure variations in subjects with normal- and high-tension glaucoma. J Glaucoma. 2003;12:156-163.

11. Sarnoff SJ, Hardenbergh E, Whittenberger JL. Mechanism of the arterial pressure response to the Valsalva test: the basis for its use as an indicator of the intactness of the sympathetic outflow. Am J Pbysiol. 1948;154:316-327.

12. Goldberger JJ. Sympathovagal balance: how should we measure it? Am J Physiol. 1999;276:H1273-H1280.

13. Eckberg DL. Parasympathetic cardiovascular control in human disease: a critical review of methods and results. Am J Physiol. 1980;239:H581-H593.

14. Jardeh SS, Prieto TE. Evaluation of the autonomic nervous system. Phys Med Rebabil Clin N Am. 2003;14:287-305. 
15. Ewing DJ, Irving JB, Kerr F, Wildsmith JA, Clarke BF. Cardiovascular responses to sustained handgrip in normal subjects and in patients with diabetes mellitus: a test of autonomic function. Clin Sci Mol Med. 1974;46:295-306.

16. Stancak AJ, Yamamotova A, Kulls IP, Sekyra IV. Cardiovascular adjustments and pain during repeated cold pressor test. Clin Auton Res. 1996;6:83-89.

17. Victor RG, Leimbach WN Jr, Seals DR, Wallin BG, Mark AL. Effects of the cold pressor test on muscle sympathetic activity in humans. Hypertension. 1987;9:429-436.

18. Benetos A, Safar ME. Response to cold pressor test in normotensive and hypertensive patients. Am J Hypertens. 1991;4:627-629.

19. Lafleche AB, Pannier BM, Laloux B, Safar ME. Arterial response during cold pressor test in borderline hypertension. Heart Circ Pbysiol. 1998;275:409-415.

20. Drance SM, Douglas GR, Wijsman K, Schulzer M, Britton RJ. Response of blood flow to warm and cold in normal and low-tension glaucoma patients. Am J Opbthalmol. 1988;105:35-39.

21. Rojanapongpun P, Drance SM. The response of blood flow velocity in the ophthalmic artery and blood flow of the finger to warm and cold stimuli in glaucomatous patients. Graefes Arch Clin Exp Ophthalmol. 1993;231:375-377.

22. Broadway DC, Drance SM. Glaucoma and vasospasm. Br J Ophthalmol. 1998;82:862-870.

23. Nicolela MT, Ferrier SN, Morrison CA, et al. Effects of cold-induced vasospasm in glaucoma: the role of endothelin-1. Invest Opbthalmol Vis Sci. 2003;44:2565-2572.

24. Mahler F, Saner H, Würbel H, Flammer J. Local cooling test for clinical capillaroscopy in Raynaud's phenomenon, unstable angina, and vasospastic visual disorders. Vasa. 1989;18:201-204.

25. Nilsson GE, Tenland T, Oberg PA. A new instrument for continuous measurements of the tissue blood flow by light beating spectroscopy. IEEE Trans Biomed Eng BME. 1980;27:12-19.

26. Nilsson GE, Tenland T, Oberg PA. Evaluation of a laser Doppler flowmeter for measurement of a tissue blood flow. IEEE Trans Biomed Eng BME. 1980;27:597-604.

27. Edge G, Morgan $M$. The Genius infrared tympanic thermometer: an evaluation for clinical use. Br J Anaestb. 1993;48:604-607.

28. Erickson RS, Kirklin SK. Comparison of ear-based, bladder, oral, and axillary methods for core temperature measurement. Crit Care Med. 1993;21:1528-1534.

29. Michelson G, Schmauss B. Two dimensional mapping of the perfusion of the retina and optic nerve head. $\mathrm{Br} J$ Ophthalmol. 1995;79:1126-1132.

30. Michelson G, Langhans MJ, Groh MJ. Clinical investigation of the combination of a scanning laser ophthalmoscope and laser Doppler flowmeter. Ger J Ophthalmol. 1995;4:342-349.

31. Burk RO, Rohrschneider K, Noack H, Volcker HE. Are large optic nerve heads susceptible to glaucomatous damage at normal intraocular pressure? A three-dimensional study by laser scanning tomography. Graefes Arch Clin Exp Opbthalmol. 1992;230:552560.

32. Burk RO, Rohrschneider K, Takamoto T, Volcker HE, Schwartz B. Laser scanning tomography and stereophotogrammetry in threedimensional optic disc analysis. Graefes Arch Clin Exp Ophthalmol. 1993;231:193-198.

33. Rohrschneider K, Burk RO, Volcker HE. Reproducibility of topometric data acquisition in normal and glaucomatous optic nerve heads with the laser tomographic scanner. Graefes Arch Clin Exp Opbthalmol. 1993;231:457-464.

34. Bartz-Schmidt KU, Weber J, Heimann K. Validity of two dimensional data obtained with the Heidelberg retina tomograph as verified by direct measurements in normal optic nerve heads. Ger J Ophthalmol. 1994;3:400-405.

35. Iester M, Mikelberg FS, Drance SM. The effect of optic disc size on diagnostic precision with the Heidelberg Retina Tomograph. Ophthalmology. 1997;104:545-548.

36. Iester M, Broadway DC, Mikelberg FS, Drance SM. A comparison of healthy, ocular hypertensive, and glaucomatous optic disc topographic parameters. J Glaucoma. 1997;6:363-370.
37. Jonescu-Cuypers CP, Thumann G, Hilgers RD, Batz-Schmidt KU, Krott R, Krieglstein GK. Long-term fluctuations of the normalised rim/disc area ratio quotient in normal eyes. Graefes Arch Clin Exp Ophthalmol. 1999;237:181-186.

38. Weinreb RN, Lusky M, Bartsch DU, Morsman D. Effect of repetitive imaging on topographic measurements of the optic nerve head. Arch Opbthalmol. 1993;111:636-638.

39. Saruhan A, Orgül S, Kocak I, Prünte C, Flammer J. Descriptive information of topographic parameters computed at the optic nerve head with the Heidelberg retina tomograph. J Glaucoma. $1998 ; 7: 420-429$.

40. Jonescu-Cuypers CP, Chung HS, Kagemenn L, Ishii Y, Zarfati D, Harris A. New neuroretinal rim blood flow evaluation method combining Heidelberg retina flowmetry and tomography. $\mathrm{Br} \mathrm{J}$ Ophthalmol. 2001;85:304-309.

41. Kagemann L, Harris A, Chung HS, Evans D, Buck S, Martin B. Heidelberg retinal flowmetry: factors affecting blood flow measurement. Br J Ophthalmol. 1998;82:131-136.

42. Hosking SL, Embleton S, Cunliffe IA. Application of a local search strategy improves the detection of blood flow deficits in the neuroretinal rim of glaucoma patients using scanning laser Doppler flowmetry. Br J Ophthalmol. 2001;85:1298-1302.

43. Sehi M, Flanagan JG. The effect of image alignment on capillary blood flow measurement of the neuroretinal rim using the Heidelberg retina flowmeter. Br J Ophthalmol. 2004;88:204-206.

44. Holm S. A simple sequentially rejective multiple test procedure. Scand J Stat. 1979;6:65-70.

45. Velasco M, Gomez J, Blanco M, Rodriguez I. The cold pressor test: pharmacological and therapeutic aspects. Am J Ther. 1997;4:3438.

46. Lovallo $\mathrm{W}$. The cold pressor test and autonomic function: a review and integration. Psychophysiology. 1975;12:268-282.

47. Yamazaki F, Sagawa S, Torii R, Endo Y, Shikari K. Effects of acute hyperthermia on the carotid baroreflex control of heart rate in humans. Int J Biometeorol. 1997;40:200-205.

48. Yamazaki F, Sone R. Modulation of arterial baroreflex control of human rate by skin cooling and heating in humans. J Appl Pbysiol. 2000;88:393-400.

49. Gregg ME, James JE, Matyas TA, Thorsteinsson EB. Hemodynamic profile of stress-induced anticipation and recovery. Int J Psychophysiol. 1999;34:147-162.

50. Laties AM. Central retinal artery innervation: absence of adrenergic innervation to the intraocular branches. Arch Opbthalmol. 1967; 77:405-409.

51. Ye X, Laties AM, Stone RA. Peptidergic innervation of the retinal vasculature and optic nerve head. Invest Opbthalmol Vis Sci. 1990;31:1731-1737.

52. Ehinger B. Adrenergic nerves to the eye and to related structures in man and the cynomolgus monkey. Invest Ophthalmol. 1966;5: 42-52.

53. Ernest JT. Autoregulation of ocular blood flow in the distal segment of the optic nerve. In: Kriegelstein GK, Leydhecker W, eds. Glaucoma Update. Berlin: Springer-Verlag; 1979:93-97.

54. Schmetterer L, Findl O, Strenn K, et al. Effects of endothelin-1 (ET-1) on ocular hemodynamics. Curr Eye Res. 1997;16:687-692.

55. Gugleta K, Orgül S, Hasler PW, Picornell T, Gherghel D, Flammer J. Choroidal vascular reaction to hand-grip stress in subjects with vasospasm and its relevance in glaucoma. Invest Ophthalmol Vis Sci. 2003;44:1573-1580.

56. Zamir N, Maixner $\mathrm{W}$. The relationship between cardiovascular and pain regulatory systems. Ann N Y Acad Sci. 1986;467:371-384.

57. Hirsch MS, Liebert RM. The physical and psychological experience of pain: the effects of labeling and cold pressor temperature on three pain measures in college women. Pain. 1998;77:41-48.

58. Wu G, Campbell JN, Meyer RA. Effects of baseline skin temperature on pain ratings to suprathreshold temperature-controlled stimuli. Pain. 2001;90:151-156.

59. Koltyn KF, Trine MR, Stregner AJ, Tobar DA. Effect of isometric exercise on pain perception and blood pressure in men and women. Med Sci Sports Exerc. 2001;33:282-290. 
60. Cui J, Wilson TE, Shibasaki M, Hodges NA, Crandall CG. Baroreflex modulation of muscle sympathetic nerve activity during posthandgrip muscle ischemia in humans. J Appl Physiol. 2001;91:16791686.

61. Cui J, Wilson TE, Crandall CG. Baroreflex modulation of muscle sympathetic nerve activity during cold pressor test in humans. Am J Pbysiol. 2002;282:H1717-H1723.

62. Michelson G, Schmauss B, Langhans MJ, Harazny J, Groh MJM Principle, validity, and reliability of scanning laser Doppler flowmetry. J Glaucoma. 1996;5:99-105.

63. Chauhan BC, Smith FM. Confocal scanning laser Doppler flowmetry: experiments in a model flow system. J Glaucoma. 1997;6:237-245.

64. Bohdanecka Z, Orgül S, Prünte C, Flammer J. Influence of acquisition parameters on hemodynamic measurements with the Heidelberg Retina Flowmeter at the optic disc. J Glaucoma. 1998; $151-157$.

65. Lietz A, Orgül S, Haefliger IO, Hendrickson P, Flammer J. Effect of carbogen, oxygen, and intraocular pressure on Heidelberg Retina Flowmeter parameters measured at the papilla. Ophthalmologica. 1998;212:149-152.

66. Morgan RW, Drance SM. Chronic open-angle glaucoma and ocular hypertension: an epidemiologic study. Br J Opbthalmol. 1975;59: 211-215.
67. Carter CJ, Brooks DE, Doyle DL, Drance SM. Investigations into a vascular etiology for low-tension glaucoma. Opbthalmology. 1990; 97:49-55

68. Schulzer M, Drance SM, Carter CJ, Brooks DE, Douglas GR, Lau W. Biostatistical evidence for two distinct chronic open angle glaucoma populations. Br J Ophthalmol. 1990;74:196-200.

69. Klein BE, Klein R, Ritter LL. Relationship of drinking alcohol and smoking to prevalence of open-angle glaucoma. The Beaver Dam Eye Study. Ophthalmology. 1993;100:1609-1613.

70. Gasser P, Stümpfig D, Schotzau A, Ackermann-Liebrich U, Flammer J. Body mass index in glaucoma. J Glaucoma. 1999;8:8-11.

71. Chung HS, Harris A, Evans DW, Kagemann L, Garzozi HJ, Martin B. Vascular aspects in the pathophysiology of glaucomatous optic neuropathy. Surv Ophthalmol. 1999;43(suppl 1):S43-S50.

72. Anderson DR. Introductory comments on blood flow autoregulation in the optic nerve head and vascular risk factors in glaucoma. Surv Opbthalmol. 1999;43(suppl 1):S5-S9

73. Gherghel D, Orgül S, Dubler B, Lübeck P, Gugleta K, Flammer J. Is vascular regulation in the central artery altered in persons with vasospasm? Arch Ophthalmol. 1999;117:1359-1362.

74. Gherghel D, Orgül S, Gugleta K, Gekkieva M, Flammer J. Relationship between ocular perfusion pressure and retrobulbar circulation in glaucoma patients with progressive damage. Am J Ophthalmol. 2000;130:597-605. 